\title{
Horizontal and vertical profiling of soil organic carbon stock in Nagaland, North East India
}

\author{
Gaurav Mishra ${ }^{1, *}$ and Amit Kumar Gorai ${ }^{2}$ \\ ${ }^{1}$ Division of Silviculture and Forest Management, Rain Forest Research Institute, Jorhat 785 001, India \\ ${ }^{2}$ National Institute of Technology, Rourkela 769 008, India
}

The present study aims to analyse the horizontal and vertical profiles of soil organic carbon (SOC) for understanding carbon storage in the soils of Nagaland, North East India. Seventy soil profiles were excavated at different locations and samples were collected from different depths. The uniformly distributed sampling locations were selected to generate horizontal profiles of SOC and carbon stock for five different layers $(0-5$, $5-15,15-30,30-60$ and $60-100 \mathrm{~cm})$ using interpolation technique. The horizontal profile of SOC indicated that carbon stock ranged from 3.74 to 60.93 , 6.94 to $213.84,9.19$ to $276.09,14.97$ to 441.82 and 7.19 to $366.17 \mathrm{t} \mathrm{C/ha,} \mathrm{for} 0-5,5-15,15-30,30-60$ and 60 $100 \mathrm{~cm}$ soil depth respectively. The vertical profile of SOC was modelled using the exponential distribution function. The vertical profile indicated that SOC $(\%)$ decreased with increasing depth in the region. The spatial mean value of SOC was also found to decrease with soil depth, with maximum value of $25.66 \mathrm{~g} / \mathrm{kg}$ at 0-5 cm depth to minimum of $8.82 \mathrm{~g} / \mathrm{kg}$ at $60-100 \mathrm{~cm}$ depth. Furthermore, the vertical profiles for different land-use types indicated that SOC levels decreased at a lesser rate in tea garden (TG) soils in comparison to other land uses. The spatial distribution indicated that SOC levels were higher in the high-altitude areas of Nagaland. We used inverse distance weighted method to generate maps for spatial distribution of SOC stocks, which can be further used for soil carbon assessment and inventorization.

Keywords: Digital soil mapping, horizontal and vertical profiles, land-use types, soil organic carbon, spatial distribution.

SOIL organic carbon (SOC) is an important indicator of soil quality ${ }^{1}$ and plays an important role in global carbon cycle $^{2,3}$. To understand the effects of SOC in the global carbon cycle, knowledge about SOC stock distribution along the depth gradient is important, similar to SOC stocks at fixed depths ${ }^{4}$. In recent decades, assessment of SOC status has become the key issue in regional and global climate change research, as it affects greenhouse gas $(\mathrm{GHG})$ concentration in the atmosphere ${ }^{5-7}$. Therefore, $\mathrm{SOC}$ is important for recognizing the factors responsible

*For correspondence. (e-mail: gaurav.mishra215@gmail.com) for carbon loss, potential regions of carbon sequestration and most important, their use as an input for simulation studies $^{8,9}$. The usual technique employed for spatial distribution of SOC is the assessment of SOC concentration within a map unit or soil type $\mathrm{e}^{10,11}$. However, this approach provides less precise estimates of SOC due to larger landscape variations in a particular region ${ }^{12}$. To overcome this, the present study used digital soil mapping (DSM) for suitable and precise information of SOC stocks $^{13}$.

The spatial variations of SOC are not uniform for all soil types and regions, and thus are always heterogeneous in nature. Therefore, determining SOC stocks for any region is a challenging task. To determine SOC stocks, soil sampling at different depth intervals and spatial locations is necessary. It is not feasible to determine SOC values at every location of a specified region due to time and cost constraints. Therefore, prediction of SOC values at different depths and locations based upon observed data is an alternative option. A traditional soil sampling method requires collecting samples from different layers and spatial locations to derive the horizontal and vertical soil profiles. In most studies, soil samples collected from a particular depth at a particular location represent the mean soil characteristics for the sampled depth interval and location ${ }^{14}$. Therefore, variations in soil properties with depth can be represented with a discontinuous function rather than a continuous function ${ }^{15}$. However, the prediction of soil properties from a discontinuous function may give rise to errors in SOC estimations ${ }^{16}$. To overcome this problem, several approaches have been proposed for obtaining a continuous function for predicting variations of soil attributes with depth ${ }^{14,17-19}$. Jenny ${ }^{17}$ proposed that a continuous function can be derived from the data of bulk horizon samples. The study suggested that connecting the mid-point of different bulk horizon data provides a continuous function to represent SOC values at different depths. Later, more sophisticated models like exponential decay functions ${ }^{19}$, polynomials of various orders (second, third, fourth and fifth), linear regression $^{20}$, random forest model $^{21}$ and equal area splines $^{16,18}$ were developed for prediction of soil characteristics with depth. According to Bishop et al. ${ }^{14}$, the spline function predicts the soil characteristics with depth more accurately than any other function. Furthermore, 
Malone et al. ${ }^{18}$ revealed that the soil characteristics at different depth intervals can be fitted using spline functions in majority of soil types. Thus, the study suggested that spline function can be used for prediction of soil properties at a specific depth. The present study examined various functions like exponential, two-degree and threedegree polynomials for their effectiveness in fitting the vertical SOC profiles.

Furthermore, horizontal profiling of SOC for different depth intervals helps quantify the carbon stock in the area with limited number of soil samples. In the past, many deterministic or geo-statistical-based approaches have been used for the spatial prediction of SOC. In the deterministic approaches, the horizontal profile of soil characteristics for a certain depth interval can be generated from the observed dataset based on the inverse distance weighted method, whereas geostatistical (kriging) approaches utilize statistical properties of the observed dataset. The basic precondition of the application of geostatistics is that the variable in the medium should have good spatial correlation. Geostatistical method of interpolation is applicable only when the variable shows spatial correlation. On the other hand, deterministic method of interpolation is of two types, viz. global and local. In the global technique, prediction at unsampled location is done based on the entire dataset, whereas in local technique, the predictions are made using the neighbourhood samples only.

In the past, kriging has been used widely in SOC mapping, due to its many advantages over other interpolation methods ${ }^{22-24}$. The present study analysed both the deterministic and kriging techniques for their suitability in the horizontal profiling of SOC. There are various types of kriging methods like ordinary, indicator, and universal, but in the present study we used only the ordinary kriging method for prediction of SOC at unsampled locations.

Nagaland consists of 11 districts, viz. Kohima, Dimapur, Peren, Phek, Khipre, Tuensang, Zunheboto, Longling, Mon, Mokokchung and Wokha. The surface profile

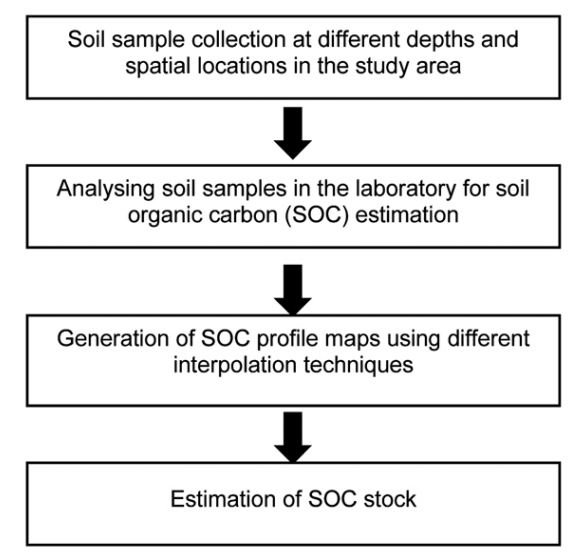

Figure 1. Flowchart of the working methodology. of the study region is narrow strip of steep incline (hilly) running northeast to southwest. The altitude of the terrain ranges between 194 and $3826 \mathrm{~m}$. The forest area coverage is $52.05 \%(860,000 \mathrm{ha})$ of the total geographic area of the region. Out of the total forest area coverage, 100,000 ha $(=11.7 \%)$ of the geographical area is owned by the state and the rest 760,000 ha $(88.3 \%)$ is private. The literature reveals that the horizontal and vertical profiles of SOC for NE India and especially for Nagaland are not available. Thus, in the present study we developed the SOC profile in the region using DSM approach to determine SOC stocks in Nagaland. This study will provide baseline information about SOC stock status of the region, which will be useful in climate change projections.

\section{Materials and methodology}

This study was carried out in four major stages. Figure 1 shows flowchart of the working methodology.

\section{Study area}

The study region selected was the entire state of Nagaland (Figure 2). The geographic area coverage of the region is $1,660,000$ ha. The latitude and longitude of the area range from $25^{\circ} 10^{\prime} \mathrm{N}$ to $27^{\circ} 4^{\prime} \mathrm{N}$ and $93^{\circ} 15^{\prime} \mathrm{E}$ to $95^{\circ} 15^{\prime} \mathrm{E}$ respectively.

\section{Soil sampling and analysis}

The soil sample survey was conducted from April 2013 to September 2017. A total of 70 sites were selected for soil

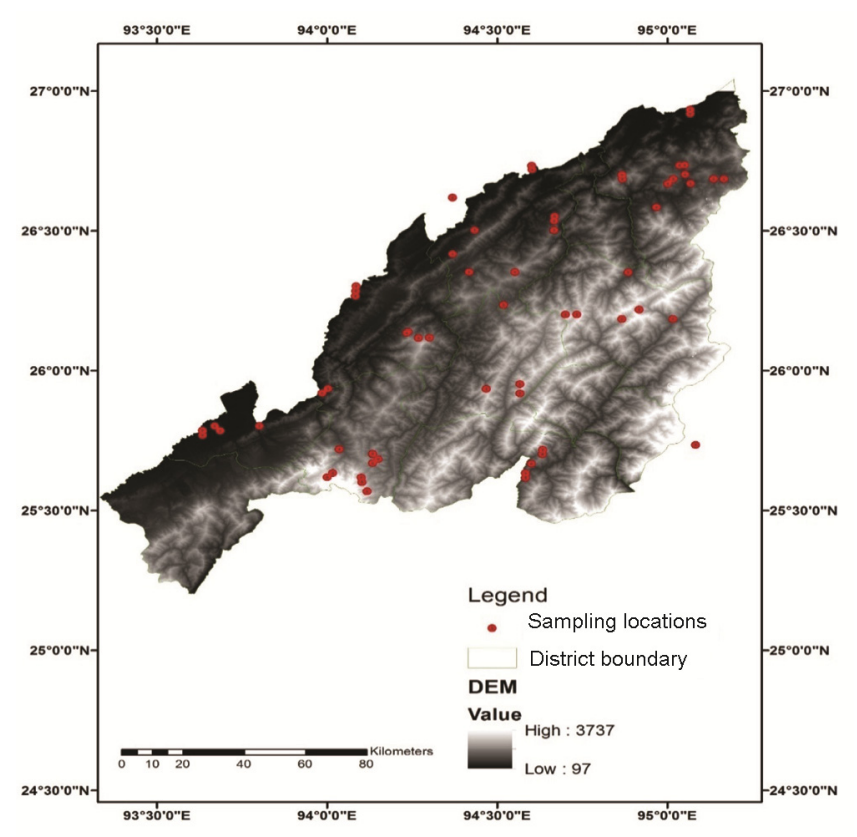

Figure 2. Location of the study area and sampling sites which are superimposed with the digital elevation model (DEM). 


\section{RESEARCH ARTICLES}

sample collection. The sampling locations were categorized into four types based on land use for analysing their effects on SOC. These are fallow jhum land (FJL), forest land (FL), jhum land (JL) and tea garden (TG). The sample sites are uniformly distributed in the study region to represent different altitude levels, gradients and floral diversity. During sample collection, site details like location name, latitude-longitude, altitude, vegetation type, slope, aspect, date of collection, etc. were recorded. In all the sampling locations, the soil was dug using a shovel to collect samples from various depth intervals $(0-5,5-15$, $15-30,30-60$ and $60-100 \mathrm{~cm})$. The soil samples from each location for different depth intervals were stored separately in polythene bags with station ID and depth ID, and then shifted to the laboratory. Later, soil samples were air-dried at room temperature $\left(27^{\circ}-28^{\circ} \mathrm{C}\right)$ for $3-4$ days until constant weight. Visible plant materials were removed and the analyses were done on the $2 \mathrm{~mm}$ dried soil fraction after sieving. The bulk density (BD) of the soil samples was estimated by the core method ${ }^{25}$. To determine SOC level, $\mathrm{K}_{2} \mathrm{Cr}_{2} \mathrm{O}_{7}$-based wet oxidation method was adopted ${ }^{26}$. The methodology for estimating SOC stock has already been described by Mishra et al. ${ }^{27}$.

\section{Vertical profiling of SOC}

The SOC data for different depth intervals were used to determine the characteristics of the vertical profile. The study analysed three types of functions, viz. exponential, two-degree polynomial, and three-degree polynomial to fit the observed SOC data at different depths for their effectiveness. It was found that the performances of the different functions were nearly the same in most of the cases. Thus, this study used the exponential function for vertical profiling of SOC level. The process was repeated for all the 70 sampled locations. The results revealed that the performances were nearly the same for all the models, and thus the exponential function was used to fit the SOC data for vertical profiling at all the sampling sites. The parameters of the exponential distribution function were determined separately for all the 70 sampling locations by fitting the respective observed SOC data to a depth of $100 \mathrm{~cm}$. These exponential functions were further used to determine the SOC content at mean values of five depth intervals of $0-5,5-15,15-30,30-60$ and $60-100 \mathrm{~cm}$, which are the standard depths specified in the Global Soil Map project (Global Soil Map 2011). Figure 3 shows an example of three sampling locations (S1, S2 and S3).

\section{Horizontal profiling of SOC}

The horizontal profiles of SOC for different depth intervals were derived using spatial modelling approach in geographical information system (GIS) platform. In the past, GIS-based surface profiling using various interpola- tion techniques like inverse distance weighted (IDW), geostatistical or kriging and land-use regression modelling has been explored in various studies. In the present study, two interpolation techniques (IDW and ordinary kriging) have been used for the prediction of SOC level at unsampled locations. To predict SOC at unsampled locations, IDW uses the observed SOC data of the neighbourhood area. In the IDW method, the influence of distance of the observed location from the prediction location is considered. The observed location which is at a small distance from the prediction location has higher weights and vice versa. On the other hand, the kriging method is a type of optimal interpolation technique for data, which have the characteristics of normal distribution, stationary and free from trends. It starts with a semi-variance analysis, in which the degree of spatial correlation can be represented as a variogram.

\section{Results and discussion}

\section{Descriptive statistics of SOC data}

Table 1 presents the descriptive statistics of SOC, BD and carbon stock data at different depths. The mean SOC content decreased with depth gradient, and organic carbon (OC) $(0.88 \%)$ at $60-100 \mathrm{~cm}$ was about three times lower than OC in the $0-5 \mathrm{~cm}$ layer (2.57). Moreover, the standard deviation (SD) of OC content was also found to decrease with depth. The OC data were positively skewed at all soil depths with a maximum skewness coefficient (1.83) at $60-100 \mathrm{~cm}$. The mean BD value in the soil was found to increase with depth. It was $0.92 \mathrm{~g} \mathrm{~cm}^{-3}$ in the 0 $5 \mathrm{~cm}$ layer and increased up to $1.02 \mathrm{~g} \mathrm{~cm}^{-3}$ in $60-100 \mathrm{~cm}$ soil depth. The mean $\mathrm{BD}$ for $\mathrm{SD}$ of $0-5 \mathrm{~cm}$ was $0.13 \mathrm{~g} \mathrm{~cm}^{-3}$ and that of $60-100 \mathrm{~cm}$ was $0.12 \mathrm{~g} \mathrm{~cm}^{-3}$. The mean value of SOC stock was also found to increase with soil depth, with minimum value of $11.22 \mathrm{t} \mathrm{Cha}^{-1}$ at $0-5 \mathrm{~cm}$ depth to maximum value of $41.79 \mathrm{t} \mathrm{C} \mathrm{ha}^{-1}$

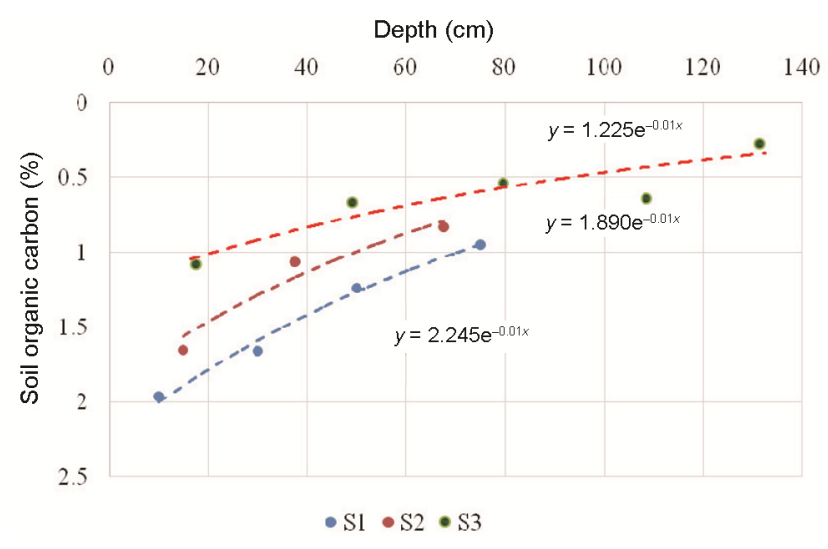

Figure 3. Example of model-fitting using measured data at three different sampling locations. 
Table 1. Descriptive statistics of spatial soil organic carbon (SOC) (\%), SOC stock and bulk density in Nagaland, North East India

\begin{tabular}{|c|c|c|c|c|c|}
\hline \multirow[b]{2}{*}{ Indicators } & \multicolumn{5}{|c|}{ Soil depth (cm) } \\
\hline & $0-5$ & $5-15$ & $15-30$ & $30-60$ & $60-100$ \\
\hline \multicolumn{6}{|l|}{$\operatorname{SOC}(\%)$} \\
\hline Minimum & 0.75 & 0.69 & 0.61 & 0.49 & 0.17 \\
\hline Maximum & 5.77 & 4.90 & 4.22 & 3.30 & 2.99 \\
\hline Mean \pm SD & $2.57 \pm 1.27$ & $2.28 \pm 1.07$ & $1.88 \pm 0.85$ & $1.37 \pm 0.66$ & $0.88 \pm 0.55$ \\
\hline \multicolumn{6}{|c|}{ Bulk density $\left(\mathrm{g} / \mathrm{cm}^{3}\right)$} \\
\hline Minimum & 0.56 & 0.56 & 0.60 & 0.71 & 0.67 \\
\hline Maximum & 1.15 & 1.15 & 1.18 & 1.25 & 1.32 \\
\hline Mean \pm SD & $0.92 \pm 0.13$ & $0.92 \pm 0.13$ & $0.94 \pm 0.14$ & $0.99 \pm 0.12$ & $1.02 \pm 0.12$ \\
\hline \multicolumn{6}{|l|}{$\operatorname{SOC}(g / k g)$} \\
\hline Minimum & 7.46 & 6.92 & 6.11 & 4.87 & 1.68 \\
\hline Maximum & 57.75 & 49.05 & 42.21 & 32.96 & 29.88 \\
\hline Mean $\pm \mathrm{SD}$ & $25.66 \pm 12.65$ & $22.78 \pm 10.67$ & $18.84 \pm 8.50$ & $13.71 \pm 6.63$ & $8.82 \pm 5.54$ \\
\hline
\end{tabular}

Table 2. SOC stock $\left(\mathrm{t} \mathrm{C} \mathrm{ha}^{-1}\right)$ distribution at different depths in Nagaland

\begin{tabular}{lccccc}
\hline & \multicolumn{5}{c}{ Soil depth $(\mathrm{cm})$} \\
\cline { 2 - 6 } Indicators & $0-5$ & $5-15$ & $15-30$ & $30-60$ & $60-100$ \\
\hline Minimum & 3.74 & 6.94 & 9.19 & 14.97 & 7.20 \\
Maximum & 24.67 & 37.11 & 59.44 & 110.96 & 35.03 \\
Mean \pm SD & $11.22 \pm 4.70$ & $19.93 \pm 7.71$ & $25.39 \pm 9.83$ & $39.43 \pm 16.99$ & $41.79 \pm 21.19$ \\
\hline
\end{tabular}

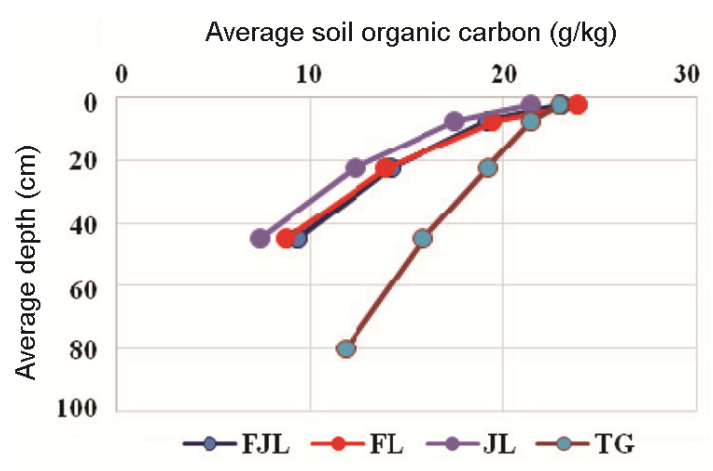

Figure 4. Vertical distribution of average SOC of different land-use types at different depths.

at $60-100 \mathrm{~cm}$ soil depth. With depth, SD value of the SOC stock also increased.

\section{SOC stocks}

The SOC stock for each sampling location for five different standard depths was determined from the observed data using eq. (1) below ${ }^{27}$

$$
\mathrm{SOC} \text { stock }=\mathrm{SOC}(\%) \times \mathrm{BD} \times D,
$$

where SOC stock represents the carbon stock ( $\left.\mathrm{t} \mathrm{Cha}^{-1}\right)$, SOC (\%) the percentage of SOC content, BD the bulk density $\left(\mathrm{g} \mathrm{cm}^{-3}\right)$ and $D$ is the thickness of the soil layer (cm). Table 2 shows the descriptive statistics of the spatial data. The mean value of SOC stock was also found to increase with soil depth, with minimum value of 11.22 $(\mathrm{t} \mathrm{C} \mathrm{ha-1)} \mathrm{at} 0-5 \mathrm{~cm}$ depth to maximum value of 41.79 ( $\mathrm{C} \mathrm{ha}^{-1}$ ) at $60-100 \mathrm{~cm}$ depth. With depth, SD value of the SOC stock also increased.

Table 3 shows the descriptive statistics of SOC for different depths determined for different land-use types. The SOC values were predicted for different depths using the corresponding predictor equations at each of the 70 sampling locations. Figure 4 shows the trend of SOC contents with depth for different land-use types. The vertical profiles indicate that $\operatorname{SOC}(\%)$ decreases with increasing depth in all the sampling locations of the study region. The mean SOC levels decrease from $24.17 \mathrm{~g} / \mathrm{kg}$ at 0 $50 \mathrm{~cm}$ depth to $7.46 \mathrm{~g} / \mathrm{kg}$ at $60-100 \mathrm{~cm}$ depth; $25.69 \mathrm{~g} / \mathrm{kg}$ at $0-50 \mathrm{~cm}$ depth to $9.40 \mathrm{~g} / \mathrm{kg}$ at $60-100 \mathrm{~cm} \mathrm{depth;}$ $26.97 \mathrm{~g} / \mathrm{kg}$ at $0-50 \mathrm{~cm}$ depth to $8.80 \mathrm{~g} / \mathrm{kg}$ at $60-100 \mathrm{~cm}$ depth; $22.83 \mathrm{~g} / \mathrm{kg}$ at $0-50 \mathrm{~cm}$ depth to $11.83 \mathrm{~g} / \mathrm{kg}$ at 60 $100 \mathrm{~cm}$ depth respectively, for JL, FJL, FL and TG land uses. The vertical profiles for different land-use types indicate that SOC levels decrease at a lesser rate in TG in comparison to the other three types. The decreasing rates are nearly the same for FL and FJL. The variations in SOC content among the different land uses of NE India were also described by Choudhury et al. ${ }^{28}$, who reported that grasslands and forests may contain very high amounts of SOC $(>2.5 \%)$ in comparison to agriculture (including lowland paddy) and shifting cultivation areas. 
Table 3. SOC (\%) and SOC stock at various depths in different land-use types of Nagaland

\begin{tabular}{|c|c|c|c|c|c|c|c|c|c|c|}
\hline \multirow[b]{2}{*}{ Indicators } & \multicolumn{5}{|c|}{$\mathrm{SOC}(\mathrm{g} / \mathrm{kg})$} & \multicolumn{5}{|c|}{$\operatorname{SOC}\left(\mathrm{t} \mathrm{C} \mathrm{ha}^{-1}\right)$} \\
\hline & $0-5 \mathrm{~cm}$ & $5-15 \mathrm{~cm}$ & $15-30 \mathrm{~cm}$ & $30-60 \mathrm{~cm}$ & $60-100 \mathrm{~cm}$ & $0-5 \mathrm{~cm}$ & $5-15 \mathrm{~cm}$ & $15-30 \mathrm{~cm}$ & $30-60 \mathrm{~cm}$ & $60-100 \mathrm{~cm}$ \\
\hline \multicolumn{11}{|l|}{ Jhum land (JL) } \\
\hline Minimum & 7.80 & 7.29 & 6.52 & 5.06 & 3.10 & 4.14 & 7.73 & 10.36 & 16.93 & 15.06 \\
\hline Maximum & 57.75 & 48.24 & 35.73 & 20.82 & 11.77 & 20.79 & 34.73 & 38.59 & 52.76 & 45.21 \\
\hline Mean & 24.17 & 21.36 & 17.47 & 12.35 & 7.46 & 10.31 & 18.29 & 22.96 & 35.52 & 30.08 \\
\hline $\begin{array}{l}\text { Standard } \\
\text { deviation }\end{array}$ & 14.04 & 11.46 & 8.20 & 4.71 & 2.63 & 4.76 & 7.62 & 8.03 & 11.22 & 9.67 \\
\hline \multicolumn{11}{|c|}{ Fallow jhum land (FJL) } \\
\hline Minimum & 11.16 & 11.08 & 10.94 & 6.14 & 1.68 & 6.31 & 12.30 & 16.74 & 18.80 & 7.20 \\
\hline Maximum & 39.49 & 32.98 & 28.86 & 26.98 & 24.29 & 16.59 & 27.71 & 33.77 & 72.85 & 87.45 \\
\hline Mean & 25.69 & 22.91 & 19.11 & 14.15 & 9.40 & 11.12 & 19.84 & 24.93 & 39.45 & 36.36 \\
\hline $\begin{array}{l}\text { Standard } \\
\text { deviation }\end{array}$ & 7.40 & 6.22 & 5.36 & 5.27 & 5.45 & 2.57 & 4.14 & 5.39 & 12.70 & 19.14 \\
\hline \multicolumn{11}{|c|}{ Forest land (FL) } \\
\hline Maximum & 55.44 & 49.05 & 42.21 & 32.23 & 29.88 & 24.67 & 37.11 & 59.44 & 110.96 & 136.63 \\
\hline Mean & 26.97 & 23.76 & 19.42 & 13.90 & 8.80 & 11.93 & 21.00 & 26.88 & 40.69 & 35.46 \\
\hline $\begin{array}{l}\text { Standard } \\
\text { deviation }\end{array}$ & 13.27 & 11.14 & 8.91 & 7.07 & 5.96 & 5.06 & 8.12 & 10.90 & 19.16 & 24.88 \\
\hline \multicolumn{11}{|c|}{ Tea garden (TG) } \\
\hline Minimum & 7.46 & 6.92 & 6.11 & 4.88 & 3.44 & 3.74 & 6.94 & 9.19 & 14.97 & 15.34 \\
\hline Maximum & 42.53 & 40.66 & 37.72 & 32.96 & 26.71 & 17.44 & 33.34 & 44.70 & 78.10 & 89.76 \\
\hline Mean & 22.83 & 21.36 & 19.15 & 15.79 & 11.83 & 10.26 & 19.20 & 25.54 & 44.22 & 44.63 \\
\hline $\begin{array}{l}\text { Standard } \\
\text { deviation }\end{array}$ & 15.89 & 14.92 & 13.52 & 11.47 & 9.11 & 6.39 & 11.95 & 15.72 & 26.96 & 28.87 \\
\hline
\end{tabular}

Table 4. Parameters of the variogram model for SOC at different depths

\begin{tabular}{lrrrrr}
\hline & \multicolumn{5}{c}{ Soil depth (cm) } \\
\cline { 2 - 6 } Spherical variogram model characteristics & \multicolumn{1}{c}{$0-5$} & $5-15$ & $15-30$ & $30-60$ & $60-100$ \\
\hline Range & 0.83 & 0.65 & 0.65 & 0.65 & 1.64 \\
Nugget & 51.43 & 1409.41 & 1379.83 & 2385.02 & 3864.48 \\
Partial sill & 14.82 & 0.00 & 0.00 & 0.00 & 0.00 \\
Sill & 66.26 & 1409.41 & 1379.83 & 2385.02 & 3864.48 \\
Nugget/sill & 0.78 & 1.00 & 1.00 & 1.00 & 1.00 \\
Lag value & 0.102 & 0.081 & 0.081 & 0.081 & 0.204 \\
\hline
\end{tabular}

\section{Horizontal profiling of SOC stocks}

The soil samples collected for five different depths $(0-5$, $5-15,15-30,30-60$ and $60-100 \mathrm{~cm})$ at 70 locations were utilized for deriving the horizontal profile of SOC using spatial analysis. Figure 2 shows the sampling locations. Before applying the interpolation technique for prediction of SOC at unsampled locations, an exploratory analysis of the observed data was done. It is important to examine the data before applying any interpolation technique for predictions at unsampled locations. In the present study, exploratory analysis of the observed data was performed to examine the consistency of data, outliers, and distribution of data. It is well known that the kriging method performs best for normally distributed data. Thus, when data do not follow normal distribution it is always desirable to transform them. To examine the normality of data, $Q-Q$ plot test was conducted. Figure $5 a-e$ shows $Q-Q$ plots for data of each layer. The results indicate that the observed data significantly deviate from the normal line for each layer.

To examine the spatial dependence of SOC data, semivariogram model was fitted for each depth in the study region. In the present study, a spherical semi-variogram model was fitted for prediction of SOC at unsampled locations for each depth interval. Table 4 lists the semivariogram characteristics like sill, nugget, range and lag for five layers. The spatial dependence of SOC levels was examined based on the ratio of nugget variance to sill expressed in percentage. It is known that the spatial dependence of SOC is strong, if the ratio is below $25 \%$. If the ratio lies between $25 \%$ and $75 \%$, the spatial dependence is moderate and when it is greater than $75 \%$, the variables show weak spatial dependence ${ }^{29}$. The results revealed that nugget variance to sill was $100 \%$ for all cases, except $0-5 \mathrm{~cm}$ depth. For this depth, the value was $78 \%$. This indicates that the data have weak spatial dependence. Thus, the exploratory data analyses indicate that the 

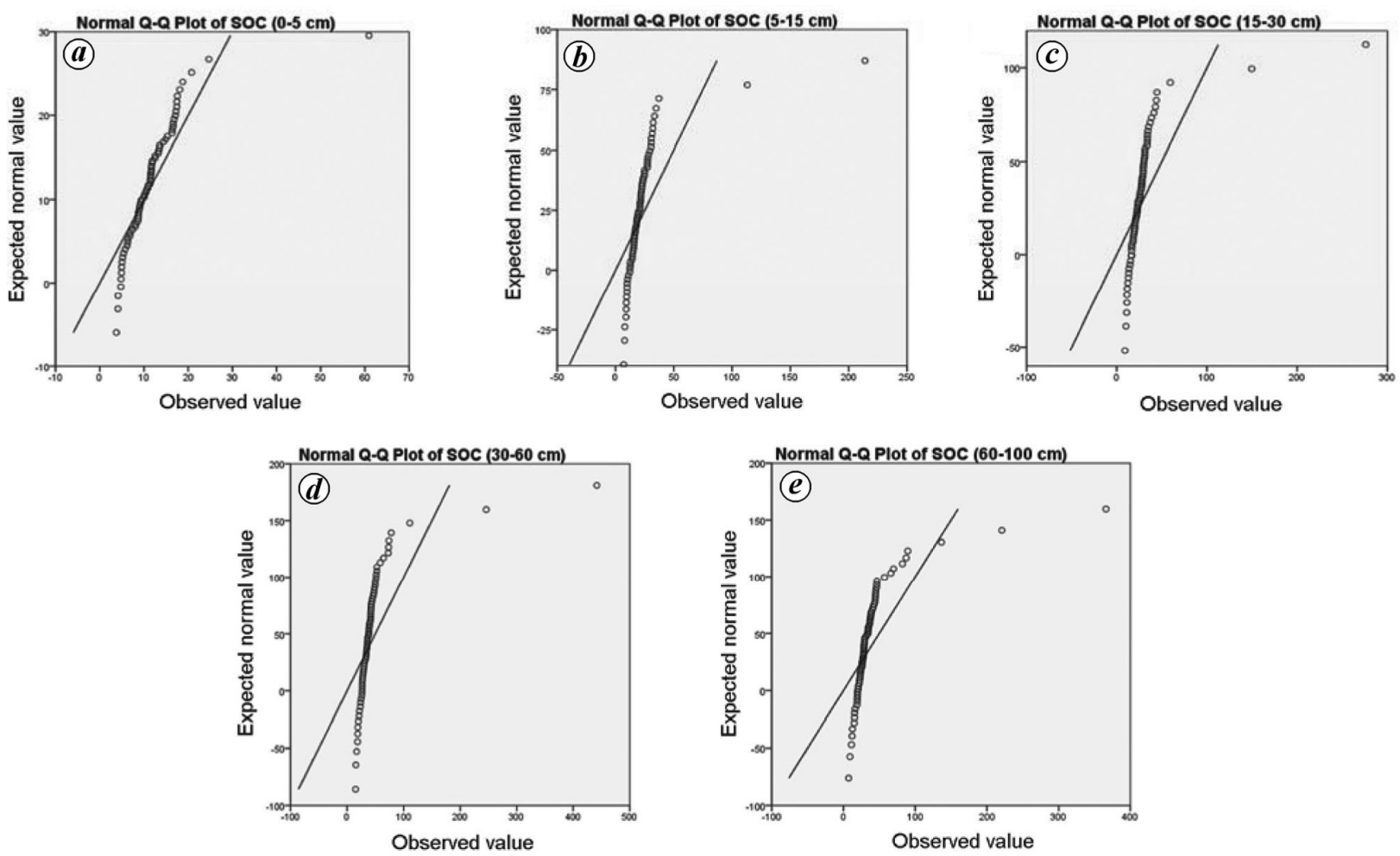

Figure 5. $Q-Q$ plots of $S O C$ at different layers: (a) $0-5 \mathrm{~cm},(\boldsymbol{b}) 5-15 \mathrm{~cm},(\boldsymbol{c}) 15-30 \mathrm{~cm},(\boldsymbol{d}) 30-60 \mathrm{~cm}$ and $(\boldsymbol{e}) 60-100 \mathrm{~cm}$.

Table 5. Root mean square error (RMSE) values of predicted data using inverse distance weighted method

\begin{tabular}{lcc}
\hline & SOC $(\%)$ & SOC stock (t/ha) \\
\cline { 2 - 3 } Soil depth $(\mathrm{cm})$ & RMSE & RMSE \\
\hline $0-5$ & 1.27 & 7.50 \\
$5-15$ & 1.03 & 35.09 \\
$15-30$ & 0.78 & 45.39 \\
$30-60$ & 0.60 & 73.75 \\
$60-100$ & 0.54 & 62.10 \\
\hline
\end{tabular}

kriging method of interpolation is not suitable for prediction of SOC at unsampled location. Therefore, the IDW method of interpolation was used to generate the horizontal profile of SOC levels at unknown points in the study region.

The IDW technique assigns more weights to the observed data points closer to the prediction location than those further away. That is, the model assumes that each observed point has a local influence on the prediction, and this diminishes with distance. The prediction of variables at any unsampled location using the IDW technique can be done using the following equation

$$
Z_{j}=\frac{\sum_{i} \frac{Z_{i}}{d_{i j}^{n}}}{\sum_{i} \frac{1}{d_{i j}^{n}}} .
$$

The model performance was evaluated using root mean square error (RMSE) value. The RMSE value can be determined using the following equation

$$
\mathrm{RMSE}=\sqrt{\frac{\sum_{i=1}^{n}\left(X_{\mathrm{obs}, i}-X_{\mathrm{model}, i}\right)^{2}}{n}} .
$$

The performances of the fitted semi-variogram models were examined based on RMSE values (Table 5). The horizontal profiles of SOC $(\%)$ and SOC stock were derived using the IDW method for five standard depth intervals in the study area. The analysis was done using Geostatistical Analyst module of ArcGIS software version 10.3. Figures 6 and 7 show the spatial distribution maps of SOC (\%) and SOC stocks for five layers respectively. The spatial maps (Figure 6) indicate that SOC (\%) is higher for $0-5 \mathrm{~cm}$ soil layer and decreases with depth of soil layer. It is also observed that $\mathrm{SOC}(\%)$ is higher in the eastern part of the study area. It can also be inferred from Figures 2 and 6 that $\operatorname{SOC}(\%)$ is higher in the highaltitude zones in comparison to lower altitudes. The spatial distribution maps of SOC stock indicate that the carbon stock ranges from 3.74 to $60.93,6.94$ to $213.84,9.19$ to $276.09,14.97$ to 441.82 and 7.19 to $366.17 \mathrm{t} \mathrm{C/ha} \mathrm{respec-}$ tively, for $0-5,5-15,15-30,30-60$ and $60-100 \mathrm{~cm}$. The spatial variation of SOC stock in Nagaland might be due to altitudinal and land-use variations in NE India ${ }^{30}$. 

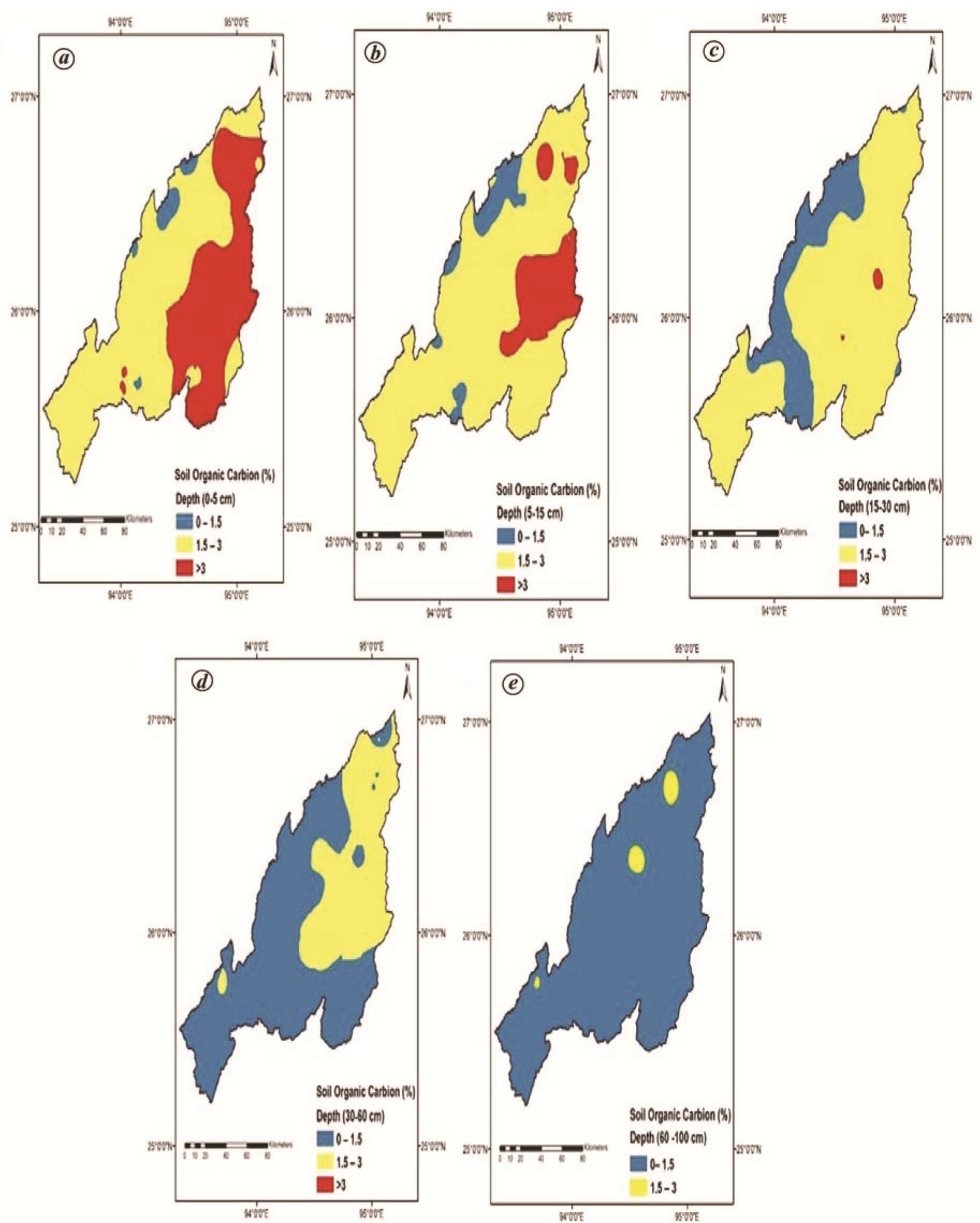

Figure 6. SOC concentration at different depths: $\boldsymbol{a}, 0-5 \mathrm{~cm} ; \boldsymbol{b}, 5-15 \mathrm{~cm} ; \boldsymbol{c}, 15-30 \mathrm{~cm} ; \boldsymbol{d}, 30-60 \mathrm{~cm} ; \boldsymbol{e}, 60-100 \mathrm{~cm}$.

\section{Conclusion}

The vertical profile and spatial distribution of SOC were analysed for estimating carbon stock in the hilly region of Nagaland. The vertical profiles indicate that SOC (\%) decreases with increasing depth in the region. The observed SOC data for different depths could be fitted suitably using exponential distribution function. The vertical profiles for different land-use types indicate that SOC levels decrease at a lesser rate in the TG area in comparison to the other three land types. The decreasing rates are nearly the same for FL and FJL. The spatial distribution indicates that the SOC levels are higher in the high-altitude areas. There is no spatial dependence of SOC level. The 

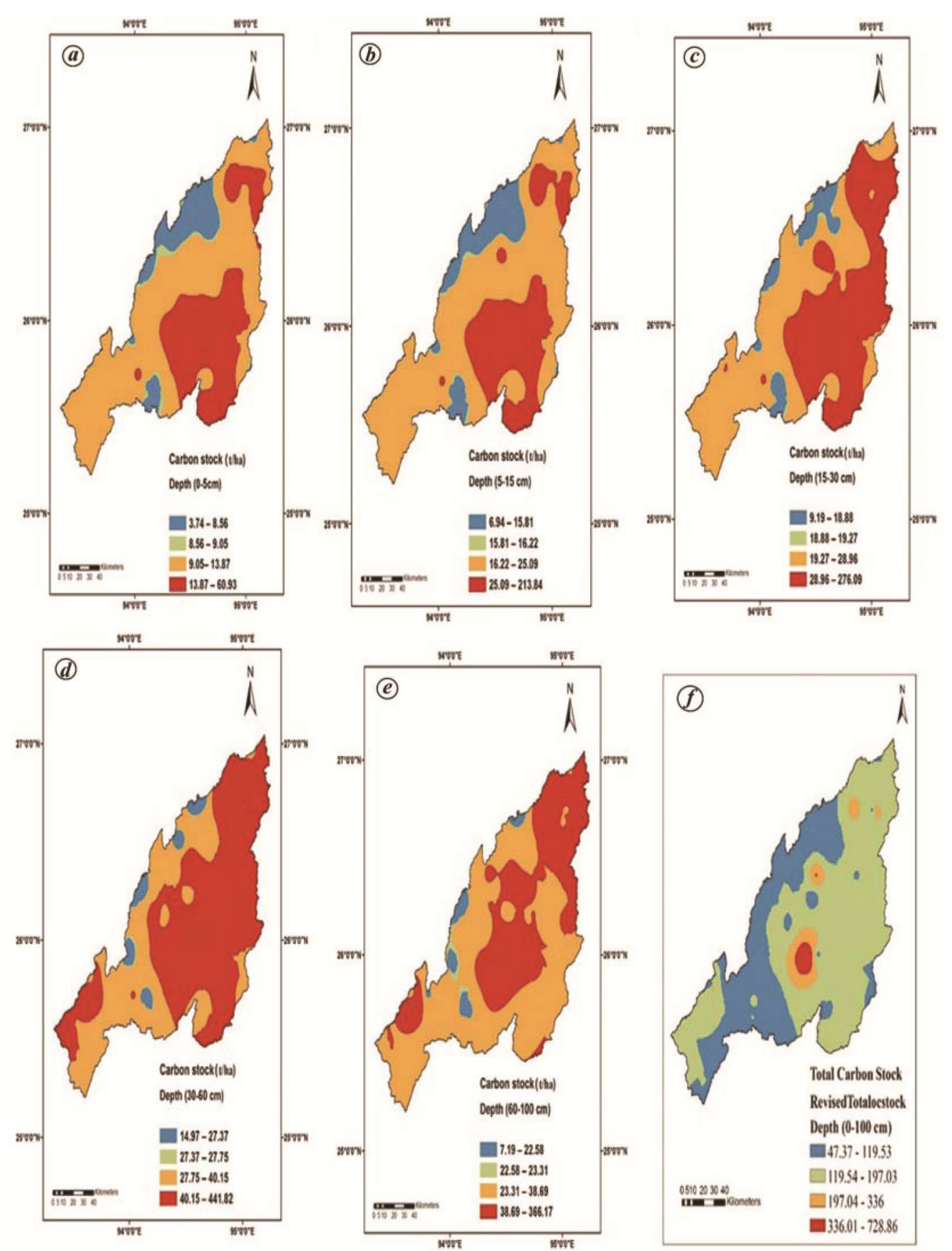

Figure 7. SOC stocks at different depths: $\boldsymbol{a}, 0-5 \mathrm{~cm} ; \boldsymbol{b}, 5-15 \mathrm{~cm} ; \boldsymbol{c}, 15-30 \mathrm{~cm} ; \boldsymbol{d}, 30-60 \mathrm{~cm} ; \boldsymbol{e}, 60-100 \mathrm{~cm} ; \boldsymbol{f}, 0-100 \mathrm{~cm}$.

present study provides information about spatial distribution of SOC stocks in Nagaland, which could help in better land-use management plans to minimize SOC losses from different land uses.

1. Johnston, C. A., Groffman, P., Breshears, D. D., Cardon, Z. G., Currie, W. and Emanuel, W., Carbon cycling in soil. Front. Ecol. Environ., 2004, 2, 522-528.
2. Liu, F., Zhang, G. L., Sun, Y. J., Zhao, Y. G. and Li, D. C., Mapping the three-dimensional distribution of soil organic matter across a subtropical hilly landscape. Soil Sci. Soc. Am. J., 2013, 77, 1241-1253.

3. Wang, S., Wang, Q., Adhikari, K., Jia, S., Jin, X. and Liu, H., Spatial-temporal changes of soil organic carbon content in Wafangdian, China. Sustainability, 2016, 8(11), 1154.

4. Meersmans, J., A multiple regression approach to assess the spatial distribution of soil organic carbon (SOC) at the regional scale (Flanders, Belgium). Geoderma, 2008, 143, 1-13. 
5. Bronson, K., Zobeck, T., Chua, T. T., Acosta-Martinez, V., van Pelt, R. S. and Booker, J. D., Carbon and nitrogen pools of southern high plains cropland and grassland soils. Soil Sci. Soc. Am. J., 2004, 68(5), 1695-1704.

6. Lal, R., Soil C sequestration impacts on global climatic change and food security. Science, 2004, 304(5677), 1623-1627.

7. Stockmann, U., Adams, M. A., Crawford, J. W., Field, D. J., Henakaarchchi, N., Jenkins, M. and Wheeler, I., The knowns, known unknowns and unknowns of sequestration of soil organic carbon. Agric. Ecosyst. Environ., 2013, 164, 80-99.

8. Minasny, B., McBratney, A. B., Malone, B. P. and Wheeler, I., Digital mapping of soil carbon. Adv. Agron., 2013, 118(3), 4.

9. Wang, S., Wanga, S., Zhuang, Q., Wang, Q., Jina, X. and Hana, C., Mapping stocks of soil organic carbon and soil total nitrogen in Liaoning Province of China. Geoderma, 2017, 305, 250-263.

10. Batjes, N. H., Effects of mapped variation in soil conditions on estimates of soil carbon and nitrogen stocks for South America. Geoderma, 2000, 97, 135-144.

11. Wu, H. B., Guo, Z. T. and Peng, C. H., Distribution and storage of soil organic carbon in China. Global Biogeochem. Cycles, 2003, 17, 1048.

12. Rasmussen, C., Distribution of soil organic and inorganic carbon pools by biome and soil taxa in Arizona. Soil Sci. Soc. Am. J., 2006, 70, 256-265.

13. McBratney, A. B., Santos, M. L. M. and Minasny, B., On digital soil mapping. Geoderma, 2003, 117, 3-52.

14. Bishop, T. F. A., McBratney, A. B. and Laslett, G. M., Modelling soil attribute depth functions with equal-area quadratic smoothing splines. Geoderma, 1999, 91, 27-45.

15. Campbell, N. A., Mulcahy, M. J. and McArthur, W. M., Numerical classification of soil profiles on the basis of field morphological properties. Aust. J. Soil Res., 1970, 8, 43-58.

16. Ponce-Hernandez, R., Marriott, F. H. C. and Beckett, P. H. T., An improved method for reconstructing a soil profile from analysis of a small number of samples. J. Soil Sci., 1986, 37(3), 455-467.

17. Jenny, H., Factors of Soil Formation, McGraw-Hill, New York, USA, 1941.

18. Malone, B. P., McBratney, A. B., Minasny, B. and Laslett, G. M., Mapping continuous depth functions of soil carbon storage and available water capacity. Geoderma, 2009, 154, 138-152.

19. Minasny, B., McBratney, A. B., Mendonca-Santos, M. L., Odeh, I. O. A. and Guyon, B., Prediction and digital mapping of soil carbon storage in the lower Namoi Valley. Aust. J. Soil Res., 2006, 44(3), 233-244.
20. Colwell, J. D., A statistical-chemical characterization of four great soil groups in southern New South Wales based on orthogonal polynomials. Aust. J. Soil Res., 1970, 8, 221-238.

21. Yang, R. et al., Comparison of boosted regression tree and random forest models for mapping topsoil organic carbon concentration in an alpine ecosystem. Ecol. Indic., 2016, 60, 870-878.

22. Chen, C., Hu, K., Li, H., Yun, A. and Li, B., Three-dimensional mapping of soil organic carbon by combining Kriging method with profile depth function. PLoS ONE, 2015, 10(6), e0129038; https://doi.org/10.1371/journal.pone.0129038.

23. Chabala, L. M., Mulolwa, A. and Lungu, O., Application of ordinary Kriging in mapping soil organic carbon in Zambia. Pedosphere, 2017, 27(2), 338-343.

24. Wang, X., Li, Y., Chen, Y., Lian, J., Luo, Y. and Niu, Y., Spatial pattern of soil organic carbon and total nitrogen, and analysis of related factors in an agro-pastoral zone in Northern China. PLoS ONE, 2018, 13(5), e0197451; https://doi.org/10.1371/journal. pone.0197451.

25. Blake, G. R. and Hartge, K. H., Bulk density. In Methods of Soil Analysis Part 1, Physical and Mineralogical Methods (ed. Klute, A.), SSSA Book Series No. 5. Soil Science Society of America and American Society of Agronomy, Madison, Wisconsin, USA, 1986, 2nd edn, pp. 951-984.

26. Walkley, A. and Black, I. A., An examination of the Degtjareff method for determining soil organic matter and a proposed modification of the chromic acid titration method. Soil Sci., 1934, 37(1), 29-38.

27. Mishra, G., Jangir, A. and Francaviglia, R., Modeling soil organic carbon dynamics under shifting cultivation and forests using RothC model. Ecol. Model., 2019, 396, 33-41.

28. Choudhury, B. U., Das, P. T. and Das, A., Land use systems and soil carbon stocks - status in Northeastern region of India. In Soil Carbon Sequestration for Climate Change Mitigation and Food Security, Central Research Institute for Dry Land Agriculture, Hyderabad, 2011, pp. 31-45.

29. Shi, J. et al., Spatial distribution of heavy metals in soils: a case study of Changxing, China. Environ. Geol., 2007, 52, 1-10; https://doi.org/10.1007/s00254-006-0443-6.

30. Choudhury, B. U. et al., Spatial variability in distribution of organic carbon stocks in the soils of North East India. Curr. Sci., 2013, 104(5), 604-614.

Received 26 March 2019; revised accepted 18 May 2020

doi: $10.18520 / \mathrm{cs} / \mathrm{v} 119 / \mathrm{i} 4 / 632-640$ 